\title{
Uncontrolled Self-Medication with Venlafaxine in a Patient with Major Depressive Disorder
}

\author{
Ji-Hye Song, Bum-Hee Yu, Dongsoo Lee, Se Chang Yoon and Hong Jin Jeon $\bowtie$ \\ Department of Psychiatry, Depression Center, Samsung Medical Center, Sungkyunkwan University School of Medicine, Seoul, Korea
}

Antidepressants are known to have no significant ability to cause addiction. However, a recent study showed many individuals with mood disorders self-medicated with antidepressants to relieve symptoms. We report here a male physician, diagnosed five years ago with major depressive disorder, with insomnia, anxiousness, and chest heaviness. He began self-medicating with $150 \mathrm{mg}$ of venlafaxine daily, without any monitoring. During his most recent severe depressive episode, he was taking up to 1,500 $\mathrm{mg}$ of venlafaxine daily. Without this medication, he experienced discontinuation syndrome, which included severe anxiety, chest heaviness, and breathing difficulty, and which he judged as indicating a more severely depressed state. He also experienced overdose symptoms, such as hypertension and tachycardia. He attempted suicide with drugs that he possessed. In conclusion, careful monitoring is needed when treating patients with venlafaxine, because its discontinuation syndrome is similar to symptoms of major depressive disorder, and suicidality may result from an overdose.

Psychiatry Investig 2011;8:74-76

Key Words Venlafaxine, Major depressive disorder, Discontinuation syndrome, Suicide attempt.

\section{INTRODUCTION}

Most authorities do not regard antidepressants as causing dependency in patients with major depressive disorder, but some researchers have challenged this presumption. ${ }^{1}$ The National Epidemiologic Survey on Alcohol and Related Conditions revealed that almost one-quarter of individuals with mood disorders used alcohol or self-medication, including antidepressants, to relieve their symptoms. ${ }^{2}$

Few studies have focused on self-medication and antidepressant abuse in patients with major depressive disorder. In this paper, we report a case of a male physician who abused venlafaxine without any monitoring. The antidepressant venlafaxine inhibits the reuptake of both serotonin and norepinephrine, with a 30-fold higher affinity for serotonin than for norepinephrine. ${ }^{3}$ Venlafaxine has a short half-life of 3.5 hours, ${ }^{4}$

Received: March 3, 2010 Revised: October 25, 2010

Accepted: October 27, 2010 Available online: December 31, 2010

$\triangle$ Correspondence: Hong Jin Jeon, MD, PhD

Department of Psychiatry, Depression Center, Samsung Medical Center, Sungkyunkwan University School of Medicine, 50 Irwon-dong, Gangnam-gu, Seoul 135-710, Korea

Tel: +82-2-3410-3586, Fax: +82-2-3410-0050, E-mail: jeonhj@skku.edu

(a) This is an Open Access article distributed under the terms of the Creative Commons Attribution Non-Commercial License (http://creativecommons.org/licenses/by$\mathrm{nc} / 3.0$ ) which permits unrestricted non-commercial use, distribution, and reproduction in any medium, provided the original work is properly cited. and it can produce discontinuation syndrome if the patient abruptly stops taking it.

The individual in question read this report before we submitted it. Moreover, we have received a signed informed consent for publication from the subject of this case report.

\section{CASE}

A male physician in his mid-40s presented to an emergency center with his first suicide attempt, which he had performed by inhaling some drugs, including venlafaxine. He had no history of alcohol or illicit drug abuse.

Five years ago, he had experienced his first depressive episode, with insomnia, anxiousness, and chest heaviness (Figure 1). The heaviness had been in the epigastric area, sometimes lasted all day, and deepened under stress. He had checked himself into a hospital. While there, he was told there was nothing wrong with his heart. He had then visited a psychiatrist, who prescribed venlafaxine. However, he had not visited the clinic again, instead prescribing $150 \mathrm{mg}$ of extended-release venlafaxine for himself thereafter, which produced a partial improvement. However, he worsened again after marital conflicts and increased his venlafaxine dose to $300 \mathrm{mg}$. After he and his wife had a child, he improved, and he reduced his venlafaxine dosage to $150 \mathrm{mg}$. 


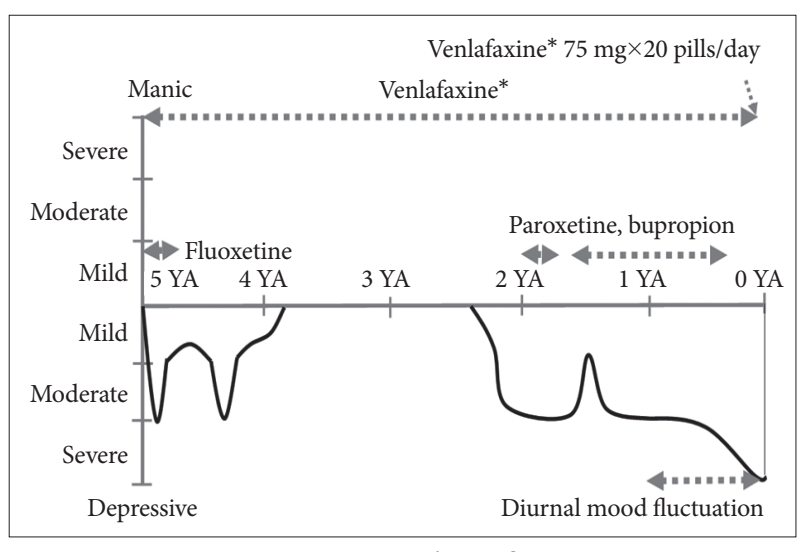

Figure 1. The patient's mood chart. *venlafaxine extended release.

Two and one-half years ago, the patient had experienced a more serious depressive episode, despite continuously taking the self-prescribed venlafaxine. His depressive episode partially eased after three months. However, one and one-half years ago, the patient's depression returned. He went back to the psychiatric clinic again, and his psychiatrist prescribed paroxetine and bupropion, which he took in addition to the self-prescribed venlafaxine. These had little effect on his mood, and he discontinued visiting the psychiatric clinic.

He judged himself as being in a more severely depressed state, because his depressive mood did not improve even though he was taking his previous dose of venlafaxine. Then, he gradually increased the venlafaxine dose, up to $1,500 \mathrm{mg}(75 \mathrm{mg} \times$ 20 pills) per day. He took most of these pills before sleeping or when he felt anxiety or depressive symptoms.

When he discontinued the venlafaxine, he experienced discontinuation syndrome: neuropsychiatric symptoms, such as depressed mood, severe anxiety, irritability, and impulsiveness; gastrointestinal symptoms, such as nausea; neuromotor symptoms, such as tremors in both hands; neurosensory symptoms, such as vertigo, paresthesias, and unbearable chest heaviness and breathing difficulty, which were most severe when he got up in the morning; vasomotor symptoms, such as diaphoresis; and other neurologic symptoms, such as insomnia, anorexia, and asthenia, as Delgado ${ }^{5}$ described.

He also experienced psychological dependence on venlafaxine. He reported feeling intense fear without venlafaxine, and he kept a large amount of it in his own home, because he had experienced seriously depressed mood and discontinuation syndrome without it. However, he never experienced an amphetamine-like high during his use.

Fifteen days prior to his visit to the emergency center, he attempted suicide with drugs that he possessed, including venlafaxine. Despite not receiving any emergency treatment at that time, he survived. He felt a lack of will to go on with everyday life or to treat himself, so he admitted himself to our ward for treatment.

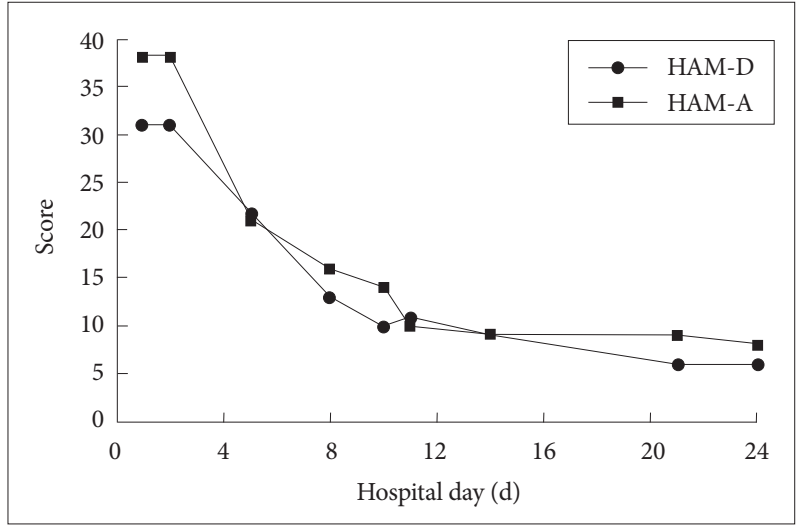

Figure 2. Course of the patient's hospital stay.

On admission, he reported both discontinuation syndrome and overdose symptoms. He experienced severe anxiety and agitation (Figure 2). He experienced poor sleep induction, and he awakened three times per sleep period, even after taking sleeping pills. He felt pain in the epigastric area. He also showed overdose symptoms, with a high blood pressure of 173/ $124 \mathrm{mmHg}$, and he took $5 \mathrm{mg}$ of amlodipine daily. His EKG was within normal ranges but showed tachycardia, with a heart rate of $110 / \mathrm{min}$. His laboratory tests, including complete blood cell count, liver and thyroid function tests, urine test, and lipid profile, were also within normal ranges. His quantitative and simple waking EEGs gave no significant findings. We estimated his cognitive functions as normal.

The patient's treatment consisted of a cessation of venlafaxine and the following prescriptions: $1 \mathrm{mg}$ of clonazepam and $100 \mathrm{mg}$ of amisulpride, for his agitation and chest discomfort; $15 \mathrm{mg}$ of mirtazapine and $25 \mathrm{mg}$ of trazodone, for depressive mood and insomnia; and $80 \mathrm{mg}$ of ginkgo biloba, for tinnitus and dizziness. After admission, he recovered from the discontinuation syndrome, overdose symptoms, and depression (Figure 2). On the 24th day, we discharged the patient with a scheduled follow-up visit at the outpatient clinic. The patient began visiting the outpatient clinic regularly and ceased to take any self-prescribed medication.

\section{DISCUSSION}

This patient continuously prescribed venlafaxine for himself for 5 years. His uncontrollable self-medication lead to severe mood fluctuations and a suicide attempt during his last depressive episode. The recommended venlafaxine dosage ranges from $150 \mathrm{mg} /$ day up to $375 \mathrm{mg} /$ day in severely depressed patients, ${ }^{6}$ but this patient took up to $1,500 \mathrm{mg} /$ day.

Self-medication of antidepressants without any monitoring is dangerous, because of the concomitant poor evaluation and management of the depression. Patients' views about depressive symptoms differ significantly from medical views, and dif- 
ferentiating "depression" from understandable reactions to adversity is difficult for patients. ${ }^{7}$ Antidepressants are also associated with the potential risk of treatment-emergent mania, hypomania, or a mixture, according to evidence from the $\mathrm{Na}$ tional Institute of Mental Health Systematic Treatment Enhancement Program for Bipolar Disorder. ${ }^{8}$

Discontinuation syndrome has been reported with nearly all antidepressants, but most commonly with venlafaxine and paroxetine. ${ }^{9,10}$ Delgado ${ }^{5}$ reported patients who discontinued serotonin reuptake inhibitor treatment tended to experience six kinds of somatic symptoms: neuropsychological, gastrointestinal, neuromotor, neurosensory, vasomotor, and other neurologic symptoms. The patients experienced all kinds of discontinuation symptoms, which are similar to symptoms of major depressive disorder. A previous study showed that antidepressant discontinuation in depressed patients sometimes correlated with worsening depression and increased suicidality. ${ }^{11}$

Venlafaxine overdose is associated with sedation, sinus tachycardia, seizures, hypertension, hypotension, diaphoresis, and hyponatremia. ${ }^{12}$ Our patient showed newly developed hypertension and tachycardia. Researchers have observed a doserelated increase in mean blood pressure with venlafaxine use, especially with doses of more than $300 \mathrm{mg}$ daily. ${ }^{13}$ Cardiac rhythm disturbances, including an increase of QTc leading to atrial fibrillation, have also been reported. ${ }^{12}$ Fatalities due to overdose of venlafaxine have also been reported. ${ }^{12,14}$

Our patient experienced both discontinuation syndrome and venlafaxine overdose symptoms, along with symptoms of major depressive disorder. He could not help but continue his self-medication, in spite of the discontinuation syndrome. This patient did not visit any clinics until his suicide attempt, because he regarded his venlafaxine overdose and withdrawal symptoms as depressive symptoms. As a physician, he had confidence that he could treat his depression without any assistance. Approximately $10 \%$ to $12 \%$ of physicians will develop a substance use disorder during their careers, a rate similar to, or exceeding, that of the general population in America. ${ }^{15-17}$

Another explanation for venlafaxine abuse is its amphetamine-like effect with large dosages, which mimics amphetamine-like highs. ${ }^{18}$ This might relate to venlafaxine's action mechanism, which blocks not only serotonin but also norepinephrine reuptake and weakly inhibits dopamine reuptake. ${ }^{6}$ However, our patient did not experience highs while taking venlafaxine.

In conclusion, venlafaxine discontinuation syndrome has symptoms similar to those of major depressive disorder, depending on each patient's experience, and an overdose may produce suicidality or a fatal outcome. Therefore, self-medication with venlafaxine should be avoided, and careful monitoring is needed when using it to treat patients with major depressive disorder.

\section{REFERENCES}

1. Haddad P. Do antidepressants have any potential to cause addiction? J Psychopharmacol 1999;13:300-307.

2. Bolton JM, Robinson J Sareen J. Self-medication of mood disorders with alcohol and drugs in the National Epidemiologic Survey on Alcohol and Related Conditions. J Affect Disord 2009;115:367-375.

3. Stahl SM, Grady MM, Moret C, Briley M. SNRIs: their pharmacology, clinical efficacy, and tolerability in comparison with other classes of antidepressants. CNS Spectr 2005;10:732-747.

4. Sadock BJ, Sadock VA. Synopsis of Psychiatry, 10th Edition. Philadelphia: Lippincott Williams \& Wilkins; 2007.

5. Delgado PL. Monoamine depletion studies: implications for antidepressant discontinuation syndrome. J Clin Psychiatry 2006;67 Suppl 4:22-26.

6. Wyeth. Venlafaxine hydrochloride. Product's label. Philadelphia, 2006.

7. Cornford CS, Hill A, Reilly J. How patients with depressive symptoms view their condition: a qualitative study. Fam Pract 2007;24:358-364.

8. Truman CJ, Goldberg JF, Ghaemi SN, Baldassano CF, Wisniewski SR, Dennehy EB, et al. Self-reported history of manic/hypomanic switch associated with antidepressant use: data from the Systematic Treatment Enhancement Program for Bipolar Disorder (STEP-BD). J Clin Psychiatry 2007;68:1472-1479.

9. Sir A, D’Souza RF, Uguz S, George T, Vahip S, Hopwood M, et al. Randomized trial of sertraline versus venlafaxine XR in major depression: efficacy and discontinuation symptoms. J Clin Psychiatry 2005;66:13121320.

10. Taylor D, Stewart S, Connolly A. Antidepressant withdrawal symptoms-telephone calls to a national medication helpline. J Affect Disord 2006;95:129-133.

11. Tint A, Haddad PM, Anderson IM. The effect of rate of antidepressant tapering on the incidence of discontinuation symptoms: a randomised study. J Psychopharmacol 2008;22:330-332.

12. Montgomery SA. Tolerability of serotonin norepinephrine reuptake inhibitor antidepressants. CNS Spectr 2008;13:27-33.

13. Feighner JP. Cardiovascular safety in depressed patients: focus on venlafaxine. J Clin Psychiatry 1995;56:574-579.

14. Long C, Crifasi J, Maginn D, Graham M, Teas S. Comparison of analytical methods in the determination of two venlafaxine fatalities. J Anal Toxicol 1997;21:166-169.

15. Berge KH, Seppala MD, Schipper AM. Chemical dependency and the physician. Mayo Clin Proc 2009;84:625-631.

16. Hughes PH, Brandenburg N, Baldwin DC Jr, Storr CL, Williams KM, Anthony JC, et al. Prevalence of substance use among US physicians. JAMA 1992;267:2333-2339.

17. McLellan AT, Skipper GS, Campbell M, DuPont RL. Five year outcomes in a cohort study of physicians treated for substance use disorders in the United States. BMJ 2008;337:a2038.

18. Sattar SP, Grant KM, Bhatia SC. A case of venlafaxine abuse. N Engl J Med 2003;348:764-765. 